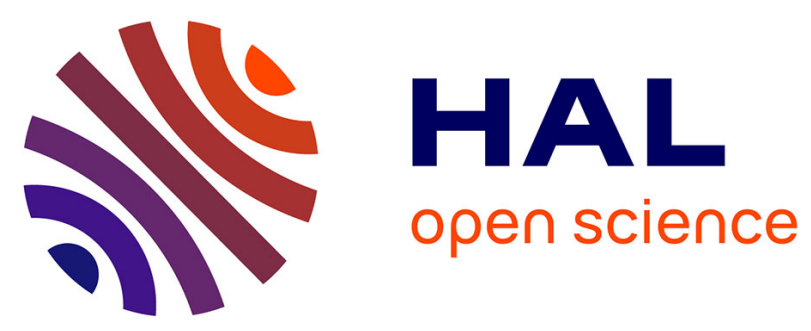

\title{
Experiments Results and Large Scale Measurement Data for Web Services Performance Assessment
}

\author{
Riadh Ben Halima, Emna Fki, Khalil Drira, Mohamed Jmaiel
}

\section{To cite this version:}

Riadh Ben Halima, Emna Fki, Khalil Drira, Mohamed Jmaiel. Experiments Results and Large Scale Measurement Data for Web Services Performance Assessment. 1st IEEE Workshop on Performance evaluation of communications in distributed systems and Web based service architectures, Jul 2009, Sousse, Tunisia. 6p. hal-00372138v2

\section{HAL Id: hal-00372138 \\ https://hal.science/hal-00372138v2}

Submitted on 14 Apr 2009

HAL is a multi-disciplinary open access archive for the deposit and dissemination of scientific research documents, whether they are published or not. The documents may come from teaching and research institutions in France or abroad, or from public or private research centers.
L'archive ouverte pluridisciplinaire HAL, est destinée au dépôt et à la diffusion de documents scientifiques de niveau recherche, publiés ou non, émanant des établissements d'enseignement et de recherche français ou étrangers, des laboratoires publics ou privés. 


\title{
Experiments Results and Large Scale Measurement Data for Web Services Performance Assessment
}

\author{
Riadh Ben Halima ${ }^{(1,2,3)}$, Emna Fki ${ }^{(3)}$, Khalil Drira ${ }^{(1,2)}$ and Mohamed Jmaiel ${ }^{(3)}$ \\ (1) CNRS ; LAAS ; 7 avenue de Colonel Roche, F-31077 Toulouse, France \\ (2) Universit de Toulouse; UPS, INSA, INP, ISAE; LAAS; F-31077 Toulouse, France \\ \{rbenhali,khalil\}@laas.fr \\ (3) University of Sfax, National School of Engineers, B.P.W, 3038 Sfax, Tunisia \\ fkiemna@yahoo.fr, Mohamed.Jmaiel@enis.rnu.tn
}

\begin{abstract}
Service provisioning is a challenging research area for the design and implementation of autonomic serviceoriented software systems. It includes automated QoS management for such systems and their applications. Monitoring and Measurement are two key features of QoS management. They are addressed in this paper as elements of a main step in provisioning of self-healing web services. In a previous work [1], we defined and implemented a generic architecture applicable for different services within different business activities. Our approach is based on meta-level communications defined as extensions of the SOAP envelope of the exchanged messages, and implemented within handlers provided by existing web service containers. Using the web services technology, we implemented a complete prototype of a service-oriented Conference Management System (CMS). We experienced our monitoring and measurement architecture using the implemented application and assessed successfully the scalability of our approach under the French grid5000. In this paper, experimental results are analyzed and concluding remarks are given.
\end{abstract}

\section{Introduction}

Internet progress has enabled data exchange between remote collaborators and the multiplication of on-line services. Several platforms of services are available today to support the design, the deployment and the implementation of these services in reduced scales of time. However, users require more exigencies. They dislike to encounter problems while using a service. Such as, waiting for a long time in order to book a room, checking whether the crashed rent car service is restored, searching for services with improved QoS. Therefore, we have to deal with these problems at the design time, and provide a strategy for recovery in order to satisfy users requirements. Such systems, have to inspect their behavior and change it when the evaluation indicates that the intended QoS is not achieved, or when a better functionality or performance is required. This implies the need of deploying entities for supervising traffic between web service providers and requesters in order to act for healing or preventing [3].

Three main steps are distinguished in the self-healing process [1]: Monitoring to extract information about the system health (using knowledge about the system configuration), Diagnosis \& Planning to detect degradations and generate repair plans, and Repair to enforce reconfiguration actions in order to heal the system. In this paper, we focus on QoS monitoring of a web service-based application. We are achieving experiments on the cooperative reviewing system which is developed in the framework of the WS-DIAMOND European project. We carry out experiment on the "conference search" web service. The monitoring is carrying out while using monitors-based approach. We present the performance measurement values and analyze experiment results. The measurement is fulfilled under the grid5000 which is an experimental grid platform gathering 3000 nodes over 8 geographically distributed sites in France.

This paper is organized as follows. Section 2 describes our self-healing architecture. Section 3 presents the monitoring framework. Section 4 details experiments and gives concluding remarks. Section 5 presents related works. The last section concludes the paper.

\section{Self-Healing Architecture}

Figure 1 shows the different self-healing modules interaction within the dynamically reconfigurable web services bus. The bus offers a flexible framework for invoking services and managing QoS.

In the following, we describe the self-healing compo- 


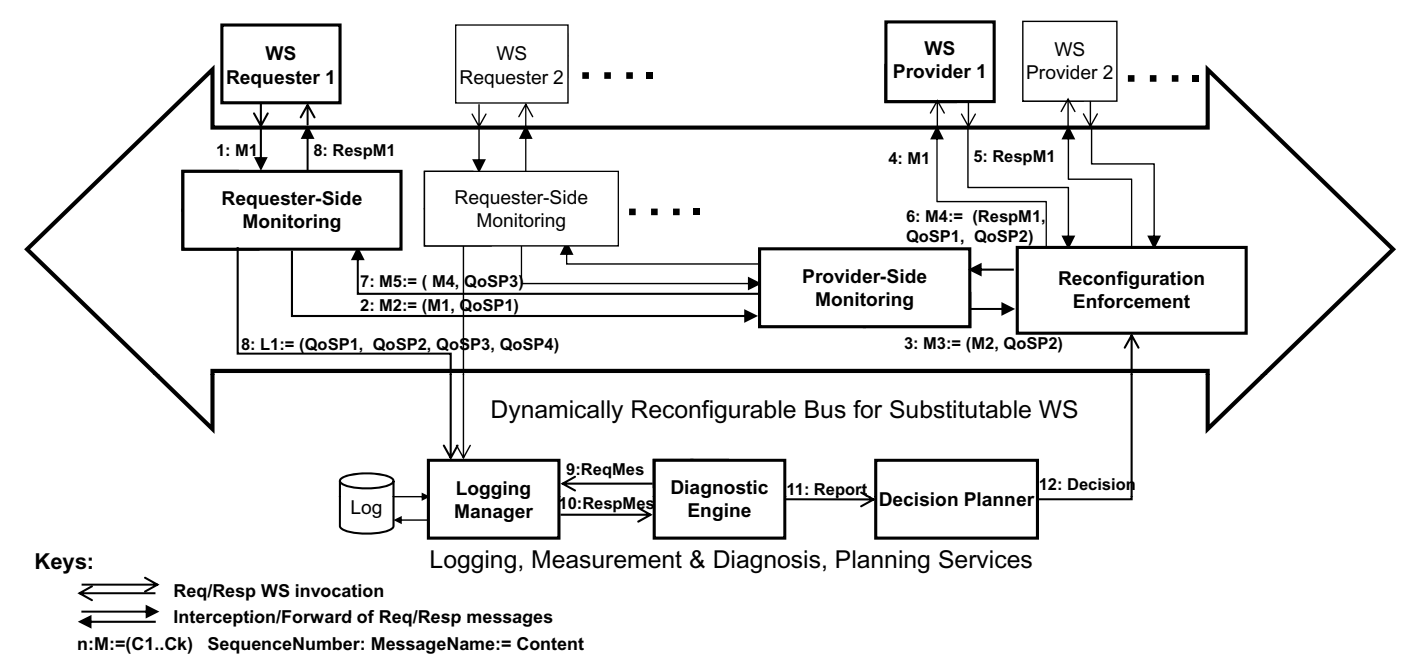

Figure 1. QoS-Oriented, Monitoring-based self-healing architecture

nents [1]:

- Monitoring \& Measurement: It observes and logs relevant QoS parameters values. It is composed of Requester-Side Monitoring(RSM), Provider-Side Monitoring ( RSM), and Logging Manager.

- Diagnostic Engine \& Decision Planner: It detects degradation and defines repair plans.

- Reconfiguration Enforcement: It enforces repair plans by rerouting requests to the suitable web service provider.

In the sequel, we present the interaction messages exchanged between the web services and the self-healing components. The WS Requester sends a request message M1. This message is intercepted by the RSM. Message MI is then extended by the first QoS parameter value ( $Q o S P 1)$ in the output message $M 2$. For example, QoSP1 may represent the invocation time of the service by the requester. Message $M 2$ is intercepted by the PSM for a second time. $M 2$ is extended by the QoS parameter value ( $Q o S P 2)$ in the output message M3. To illustrate this, QoSP2 may represent the communication time spent by the message to reach the provider-side network. The current bound WS Provider executes the request. The message response $M 4$ is intercepted by the PSM for a third extension by the QoS parameter value ( $Q o S P 3)$ in the output message M5. For example, $Q o S P 3$ may represent the execution time associated with the request. Message M5 is intercepted by the RSM. It is then extended by the fourth QoS parameter value (QoSP4). For example, QoSP4 may represent the time spent by the response to reach the requester-side. The QoS data is extracted at this connector-level and sent to the Logging Manager which is a web service responsible of saving data in a $\log$. The Diagnostic Engine questions periodically the Logging Manager, analyzes statistically $\mathrm{QoS}$ values (Messages ReqMes and RespMes), and sends alarms and diagnostic reports (Message Report) to the Reconfiguration Decision Planner. When a QoS degradation is detected, the Reconfiguration Decision Planner plans a reconfiguration and solicits REC for enforcement (Message Decision). For example, the Reconfiguration Decision Planner can ask for leaving WS Provider 1 and binding requesters to WS Provider 2. Consequently, requests will be routed to WS Provider 2 instead of WS Provider 1.

\section{QoS Monitoring Framework}

\subsection{Monitoring Approach}

Our Monitoring approach is based on Monitor which is a software entity used to intercept and to enrich SOAP messages with QoS information. A SOAP message is encapsulated in a SOAP Envelop which is divided into two parts: The Header and the Body. The SOAP Body element provides a mechanism for exchanging mandatory information like method name, parameters, and invocation result while the SOAP Header allows extension of SOAP messages [2]. The Monitor intercepts a SOAP message and enriches its Header with QoS information.

In the following:

- $t 1$ represents the time at which the request has been issued by the service requester. It denotes the value of QoSP1,

- $t 2$ represents the time at which the request has been received by the service provider. It denotes the value 
of $Q o S P 2$,

- $t 3$ represents the time at which the response has been issued by the service provider. It denotes the value of $Q o S P 3$, and

- $t 4$ represents the time at which the response has been received by the service requester. It denotes the value of QoSP4.

We interrogate the log and measure QoS values, namely: Execution Time, Communication Time, Response Time, Throughput, Availability and Scalability, according to formulas shown below:

Execution Time: The time spent by the service to execute a request; $T_{\text {exec }}=t 3-t 2$

Response Time: The time from sending a request until receiving a response; $T_{\text {resp }}=t 4-t 1$

Communication Time: The transport time of the request and the response; $T_{\text {comm }}=T_{\text {resp }}-T_{\text {exec }}$

Throughput: The number of requests served in a given period [4] which is calculated through this formulas;

Throughput $=$ Number of requests/period of time

Availability: This parameter is related to the number of failures of a service in a time interval [4]. It is calculated through this formulas:

Availability $=$ Number of successful responses/Total number of requests)

Scalability: A web service that is scalable, has the ability to not get overloaded by a massive number of parallel requests [6] (see table 3 ).

\subsection{Conference Management System}

The Cooperative Management System is concerned with a multi-services application involving massively cooperating web services. Its architecture aims to ensure data exchange flexibility between system components. It includes three tiers composed of the following components:

Requesters: They are composed of system actors namely: administrators, authors, reviewers and chairmen.

The self-healing components: They manage QoS degradation between each pair of requester/provider.

Web services: They include requester-side and provider-side web services. The requester-side web services are used by requesters to dynamically explore and invoke specific services. Provider-side web services offer functionalities related to cooperative reviewing.

The cooperative reviewing process starts by searching a suitable conference for authors. So, they send requests to the ConfSearch web service across the bus looking for appropriate conferences (topics, publisher, deadline, etc.). In this paper, we monitor QoS of the web service based Conference Management System. We interest mainly in the measurement and evaluation of QoS presented in section 3.1 for the ConfSearch web service.

\section{Experimental Environment}

To perform QoS tests of the ConfSearch web service, we used the French grid5000. The deployment architecture is shown in figure 2. The grid5000 is composed of several nodes operating with fedora linux (see table 1).

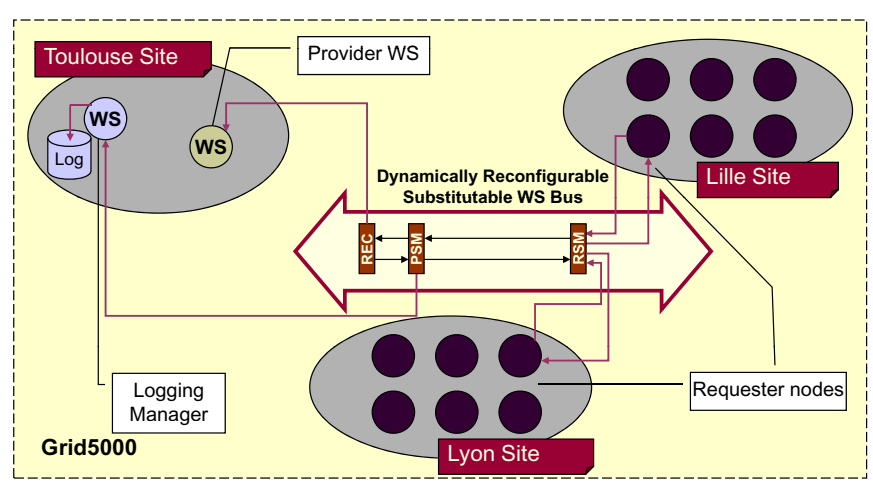

\section{Figure 2. Infrastructure of experiments}

The network configuration for the experimental environment is illustrated in table 1 . We reserved nodes located in different sites. We run two nodes for servers. The first for CMS web services and the second for the Logging Manager web service. We reserve and run respectively $1,3,5$, $10,25,50,75,100,200,350$, and 500 requesters ${ }^{1}$. We use Apache Tomcat5.5 as a web server, Axis1.4 as a SOAP engine, Java1.5 as a programming language, and MySQL5 as a database management system.

Using unix shell scripts, we can build and run multiple requesters at the same time. Each requester sends SOAP requests to the ConfSearch web service. The requester continuously invokes the services during 10 minutes. The experiments are carried out more than 10 times. Each request will be intercepted four times in order to enrich it with QoS values. Before the response reaches the requester, the $R S M$ runs a thread which logs QoS values. Based on formulas shown in section 4 , we interrogate log and compute the response and execution times, as well as availability and throughput.

Table 2 shows experiment results of the ConfSearch web service. The first line shows that 1 requester invokes the

\footnotetext{
${ }^{1}$ Experiment data are available at http://www.laas.fr/ $/$ khalil/TOOLS/QoS-4-SHWS/index.html
} 


\begin{tabular}{||l|l|l|l|l|l||}
\hline \hline \multirow{2}{*}{ Site Name } & Toulouse & \multicolumn{2}{|c||}{ Sophia } & \multirow{2}{*}{ Lyon } \\
\cline { 3 - 5 } & & Azur (cluster1) & Helios (cluster2) & & \\
\hline \hline Model & Sun Fire V20z & IBM eServer 325 & Sun Fire X4100 & IBM eServer 325 & IBM eServer 325 \\
\hline CPU & AMD Opteron 248 & AMD Opteron 246 & AMD Opteron 275 & AMD Opteron 248 & AMD Opteron 246 \\
& $2.2 \mathrm{GHz}($ dual core) & $2.0 \mathrm{GHz}$ (dual core) & $2.2 \mathrm{GHz}$ (dual core) & $2,2 \mathrm{GHz}$ (dual core) & $2.0 \mathrm{GHz}(\mathrm{dual}$ core) \\
\hline Memory & $2 \mathrm{~GB}$ & $2 \mathrm{~GB}$ & $4 \mathrm{~GB}$ & $2 \mathrm{~GB}$ & $2 \mathrm{~GB}$ \\
\hline Network speed & Gigabit Ethernet & $2 \times$ Gigabit Ethernet & 4 x Gigabit Ethernet & Gigabit Ethernet & Gigabit Ethernet \\
\hline \hline
\end{tabular}

Table 1. Grid5000 nodes configuration.

\begin{tabular}{|c|c|c|c|c|c|c|c|c|c|c|}
\hline \multirow{2}{*}{$\begin{array}{l}\text { Requesters } \\
\text { Number }\end{array}$} & \multirow{2}{*}{$\begin{array}{l}\text { Request } \\
\text { Number }\end{array}$} & \multirow{2}{*}{$\begin{array}{l}\text { Succeeded } \\
\text { Requests }\end{array}$} & \multirow{2}{*}{$\begin{array}{l}\text { Failed } \\
\text { Requests }\end{array}$} & \multirow{2}{*}{$\begin{array}{l}\text { Experiment } \\
\text { duration }\end{array}$} & \multicolumn{3}{|c|}{ Execution Time (ms) } & \multicolumn{3}{|c|}{ Communication Time (ms) } \\
\hline & & & & & Min & $\operatorname{Max}$ & Avg & Min & Max & Avg \\
\hline 1 & 6464 & 6193 & 271 & 10Min & 10 & 222 & 18,163 & 40 & 1253 & 59,767 \\
\hline 3 & 16285 & 15368 & 917 & 10Min & 10 & 654 & 22,795 & 35 & 2447 & 71,895 \\
\hline 5 & 18218 & 16903 & 1315 & 10Min & 9 & 638 & 28,496 & 35 & 155917 & 99,683 \\
\hline 10 & 29783 & 25528 & 4255 & 10Min & 9 & 964 & 55,076 & 27 & 5454 & 128,297 \\
\hline 25 & 35304 & 26337 & 8967 & 10Min & 9 & 2989 & 79,059 & 33 & 5700 & 310,039 \\
\hline 50 & 39087 & 25563 & 13524 & $10 \mathrm{Min}$ & 9 & 4903 & 87,033 & 35 & 21554 & 737,783 \\
\hline 75 & 42227 & 24554 & 17673 & 10Min & 9 & 6052 & 95,330 & 31 & 185258 & 1352,367 \\
\hline 100 & 43118 & 24380 & 18738 & 10Min & 9 & 6021 & 97,900 & 39 & 211162 & 1780,646 \\
\hline 200 & 44072 & 24084 & 19988 & 10Min & 9 & 5626 & 116,434 & 34 & 245921 & 1653,905 \\
\hline 350 & 44243 & 24869 & 19374 & 10Min & 9 & 6271 & 116,985 & 24 & 489053 & 1735,029 \\
\hline 500 & 47981 & 25736 & 22245 & 10Min & 9 & 5919 & 117,739 & 24 & 217436 & 1660,850 \\
\hline
\end{tabular}

Table 2. Performance.

ConfSearch web service for 6193 times in 10 minutes. At 500 concurrent requesters, about $50 \%$ of requests failed. We remark that the growth of requesters number leads to overload the server and to turn down the performance. However, The execution time value is monotonically increasing while the communication time is varying due to the traffic injected by other users of grid5000.

Figure 3.a displays the communication time variation according to the requester number growth. The curve keeps growing until the level of 100 requesters. After that level, it stills around 1,7 second. The communication time varies between about $100 \mathrm{~ms}$ for 10 requesters to about $2000 \mathrm{~ms}$ for 100 requesters. It increases highly with the number of requesters showing the importance of this parameter in response time observed by the requesters. Such information is being analyzed and modelled to support a correct monitoring and diagnosis for this application.

Figure 3.b shows the evolution of the execution time while increasing the requester number. It increases continuously from about $20 \mathrm{~ms}$ at 1 requester to $120 \mathrm{~ms}$ at 500 concurrent requesters. The growth of requesters number overloads the service and turns down the performance.

Figure 3.c presents the throughput variation from 1 requester to 500 requesters. It allows us to conclude that the web service can respond at the maximum of about 40 requests per second. This threshold is reached with 25 concurrent requesters and remains stable while the requesters number increases.

We have registered the number of triggered exceptions and erroneous service response. After that, we have drawn up the service availability (see figure 3.d). We point out that the 1 requester continuous invocation during 10 minutes may trigger 271 exceptions. The service responds to less than $80 \%$ of requests if the simultaneous requesters number exceeds 100 . We notice that most error responses were related to "connection refused" exceptions, which means that the application server capacity is exceeded in term of scheduling.

We classified the response time in table 3 into different intervals (in seconds): $[0,1]$ contains requests that took less than $1 \mathrm{~s},[1,2]$ includes requests that took between 1 and $2 \mathrm{~s}$, etc. We divided the number of requests of each interval by the total number of succeeded requests to get the result of the percentage in different time slots. Those percentages depict the scalability of the ConfSearch web service. The first three lines of table 3 show the execution result of 1,5 and 10 concurrent clients. Approximately, $100 \%$ of requests are served in a response time less than 1 second. When we exceed 50 clients, the web service suffers from the big number of concurrent requests and slows down its response time. For instance, about $80 \%$ of requests are completed in a response time more than 1 second at 100 and 200 concurrent requesters. We notice that the performance degrades when the number of requesters growth and the availability turns down to about $20 \%$ (see figure 3.d).

In figure 4, we drew up two curves of the response time. In the first curve, the measurement is achieved with monitors. In the second one, the measurement is done in the client code and without using monitors. Less than 50 concurrent clients, both curves are similars and the load of con- 


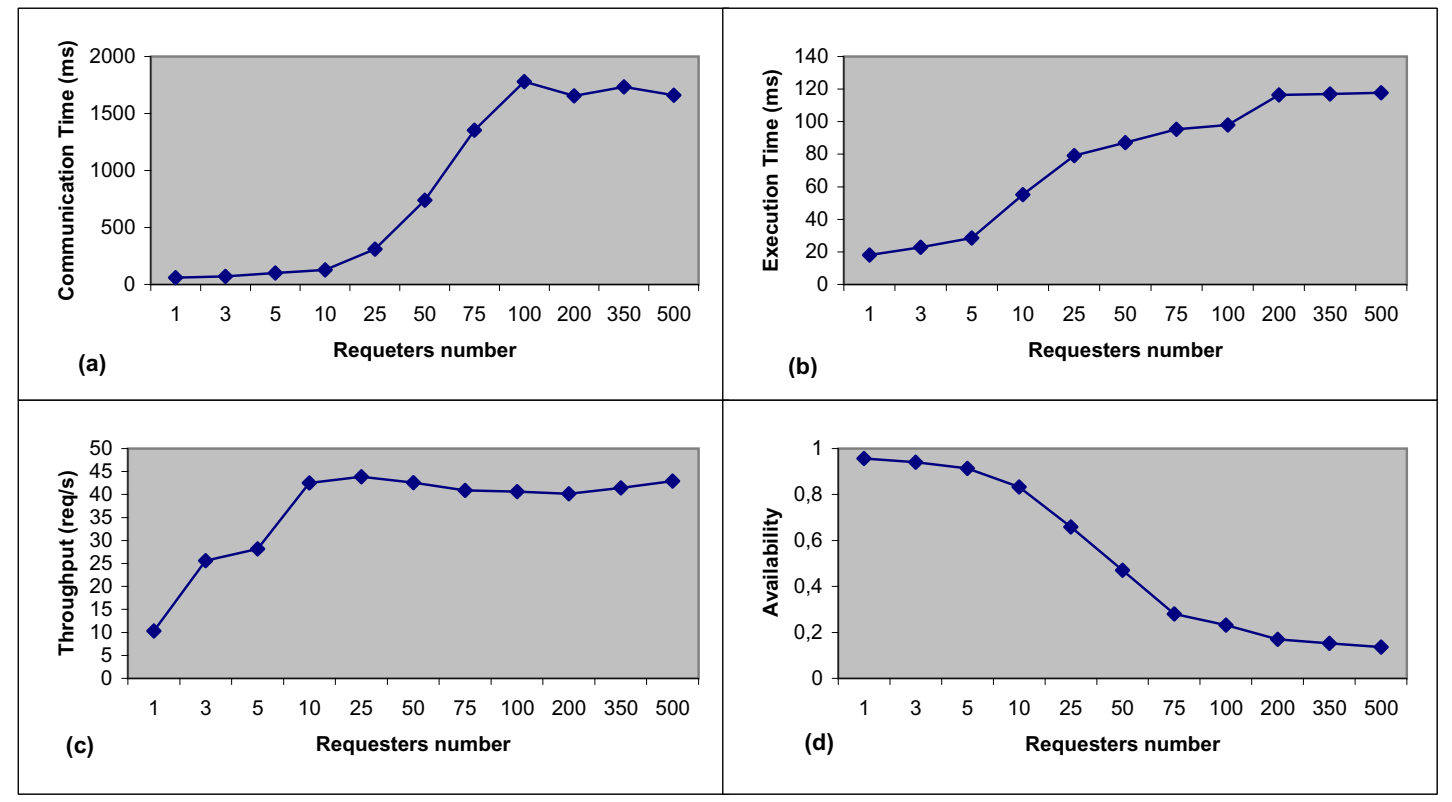

Figure 3. QoS parameters variation

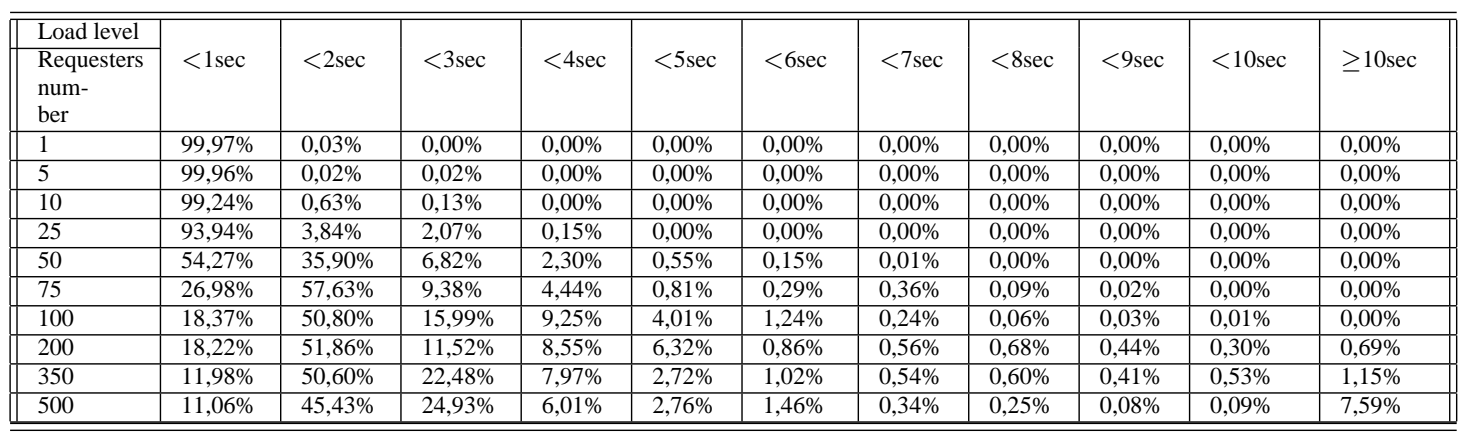

Table 3. Scalability of the ConfSearch web service.

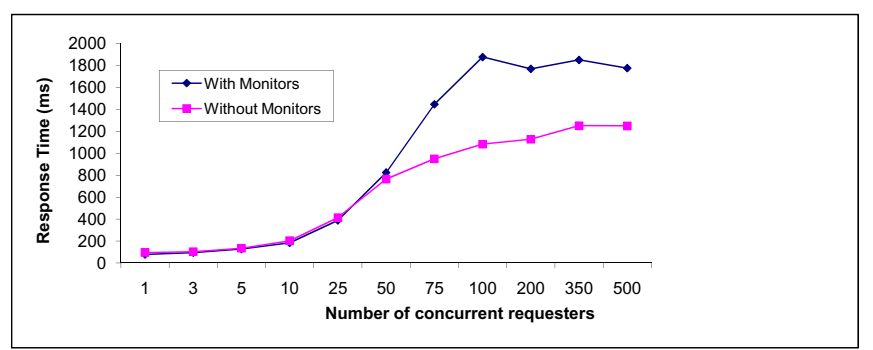

Figure 4. Load of connectors

nectors is unimportant and about zero. The delay comes to half second when we exceed 50 concurrent clients. This implies that our architecture is very suitable for a service invoked by less than 50 concurrent requesters at the same time and we have to take into account the added load when we exceed 50 concurrent requesters.

\section{Related Work}

El Saddik [7] addresses the measurement of the scalability and the performance of a web services based e-learning system. He carries out experiments on web service based e-learning system under LAN and DSL environment. He uses multi-clients system simulator which runs concurrent threads requesters. El Saddik interprets collected monitoring data. As a conclusion, he suggests a proxy-based approach for scheduling a massive flow of concurrent requests. But, this delays the problem from the server level to the proxy level. 


\begin{tabular}{|c|c|c|c|c|c|c|}
\hline & & {$[8]$} & [7] & {$[5]$} & {$[6]$} & Our Work \\
\hline \multirow{4}{*}{$\begin{array}{l}\text { Measured } \\
\text { QoS }\end{array}$} & Response Time & $\mathrm{x}$ & $\mathrm{x}$ & $\mathrm{x}$ & $\mathrm{x}$ & $\mathrm{x}$ \\
\hline & Throughput & $\mathrm{x}$ & & $x$ & & $\mathrm{x}$ \\
\hline & Scalability & & $\mathrm{x}$ & & & $\mathrm{x}$ \\
\hline & Availability & & & & $x$ & $\mathrm{x}$ \\
\hline Techniques & & $\begin{array}{l}\text { SOAP Engine Library } \\
\text { modification }\end{array}$ & $\begin{array}{l}\text { Use TestMaker tool to } \\
\text { run concurrent clients }\end{array}$ & $\begin{array}{l}\text { Analyse IP/TCP \& } \\
\text { HTTP protocols }\end{array}$ & $\begin{array}{l}\text { Aspect Oriented Pro- } \\
\text { gramming }\end{array}$ & $\begin{array}{l}\text { SOAP Message Inter- } \\
\text { ception }\end{array}$ \\
\hline web service & & $\begin{array}{l}\text { (i) Google web API, } \\
\text { (ii) Amazon Box, (iii) } \\
\text { webserviceX.net }\end{array}$ & $\begin{array}{l}\text { Own developed service } \\
\text { : e-learning services }\end{array}$ & $\begin{array}{l}\text { Own developed ser- } \\
\text { vice: not provided }\end{array}$ & $\begin{array}{l}\text { (i) Google web API, } \\
\text { (ii) CaribbeanT, (iii) } \\
\text { Zip2Geo }\end{array}$ & 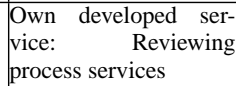 \\
\hline Deployment & & $\begin{array}{l}\text { Cable connection + In- } \\
\text { ternet ADSL } 512 \mathrm{~Kb} / \mathrm{s}\end{array}$ & $\begin{array}{l}\text { LAN } 100 \mathrm{Mb} / \mathrm{s}+\text { Inter- } \\
\text { net ADSL } 960 \mathrm{~Kb} / \mathrm{s}\end{array}$ & LAN $100 \mathrm{Mb} / \mathrm{s}$ & & Grid5000 \\
\hline $\begin{array}{l}\text { Points in } \\
\text { favour }\end{array}$ & & $\begin{array}{l}\text { Automatic measure- } \\
\text { ment }\end{array}$ & $\begin{array}{l}\text { Use of two connection } \\
\text { methods }\end{array}$ & $\begin{array}{l}\text { No modification of } \\
\text { client and service code }\end{array}$ & $\begin{array}{l}\text { Separate Measurement } \\
\text { from client code }\end{array}$ & Large-scale experiment \\
\hline $\begin{array}{l}\text { Points } \\
\text { against }\end{array}$ & & $\begin{array}{l}\text { Implementation depen- } \\
\text { dency }\end{array}$ & $\begin{array}{l}\text { The clients are run } \\
\text { from only one machine }\end{array}$ & Great CPU load & $\begin{array}{l}\text { Implementation depen- } \\
\text { dency }\end{array}$ & $\begin{array}{l}\text { Grid is closed, no con- } \\
\text { nection to google, etc. }\end{array}$ \\
\hline
\end{tabular}

Table 4. Synthesis of the related work

The work proposed in [5] presents an approach for monitoring performance across network layers as HTTP, TCP, and IP. It aims to detect faults early and reconfigures the system at real time while minimizing the substitution cost. But, the parsing of many layers takes enough time and consumes resources which will affect the performance. In addition, the experiment is fulfilled only under two nodes which will not reflect the behavior of such system in a large scale use.

Authors of [8] propose a framework for QoS measurement. They extend SOAP implementation API in order to measure and log QoS parameters values. The API modification have to be done in both sides: client and provider sides. This automates the performance measurement values. Also, it allows continuously updating information about QoS of services. An experiment is achieved with available services under the net. They run about 200 requests per day during 6 days and measure only the response time. However, this approach is dependent on the SOAP implementation. The extension have to be set up on the provider SOAP implementation which is difficult.

In [6] the authors propose both an evaluation approach for QoS attributes of web service, which is service and provider independent, and a method to analyze web service interactions and extract important QoS information without any knowledge about the service implementation. They implement their monitors using the Aspect Oriented Programming $(A O P)$. They alter the behavior of the code base by applying additional behavior at various join points in the program. However, the aspect language is dependent to the used programming language.

\section{Conclusion}

In this paper, we presented our experimental results of a large-scale web service-based application implementing the conference management and the cooperative reviewing process. This experiment aims to validate the self-healing architecture that we developed in the context of the IST WSDIAMOND project. The performance measures how QoS vary under many load conditions, and how to prevent service from QoS degradation.

The monitors load come to 0,5 second when we exceed 50 requesters. Also, when we exceed 50 requesters, the service availability turns down to less than $50 \%$. Consequently, we have to limit the number of concurrent requests addressed to a service to less than 50 requesters.

\section{References}

[1] R. BenHalima, M. Jmaiel, and K. Drira. A qos-oriented reconfigurable middleware for self-healing web services. In IEEE International Conference on Web Services (ICWS 2008), pages 104-111, Beijing (Chine), 2008. IEEE CS.

[2] M. Gudgin, M. Hadley, J.-J. Moreau, and H. F. Nielsen. Simple Object Access Protocol (SOAP). W3C, http://www.w3.org/TR/2001/WD-soap12-20010709/, 2001.

[3] J. O. Kephart and D. M. Chess. The vision of autonomic computing. Computer, 36(1):41-50, 2003.

[4] C. Patel, K. Supekar, and Y. Lee. Provisioning resilient, adaptive web services-based workflow: A semantic modeling approach. In Proceedings of the IEEE International Conference on Web Services (ICWS'04), page 480. IEEE CS, 2004.

[5] N. Repp, R. Berbner, O. Heckmann, and R. Steinmetz. A cross-layer approach to performance monitoring of web services. In Proceedings of the Workshop on Emerging Web Services Technology. CEUR-WS, Dec 2006.

[6] F. Rosenberg, C. Platzer, and S. Dustdar. Bootstrapping performance and dependability attributes ofweb services. In Proceedings of the IEEE International Conference on Web Services (ICWS'06), pages 205-212. IEEE CS, 2006.

[7] A. E. Saddik. Performance measurements of web servicesbased applications. IEEE Transactions on Instrumentation and Measurement, 55(5):1599-1605, October 2006.

[8] N. Thio and S. Karunasekera. Automatic measurement of a qos metric for web service recommendation. In Proceedings of the Australian conference on Software Engineering (ASWEC'05), pages 202-211. IEEE CS, 2005. 